\title{
A Comparison on Business Negotiation Styles with Education
}

\author{
Yu-Te Tu \\ Chungyu Institute of Technology, Taiwan \\ suntu@ms18.hinet.net
}

\begin{abstract}
Training and education is important in negotiation. For a trained negotiator, good results are the consequence of knowing when to follow to his/her instincts and when to employ negotiation theories or use a combination of them. As the economics within Greater China become more internally linked together, it becomes increasingly important to understand the nuances of each culture encompassed by this term. There is very little comparing the negotiation styles of Chinese who live in Taiwan, Hong Kong, and China among themselves. To fill the gap, the present research focuses on negotiations style comparison by education among Chinese in Taiwan, Hong Kong, and China. The population was chosen from public companies listed under the stock markets. Data was collected using an online survey technique. SPSS was used to conduct data analyses, and a variety of statistical measures were used, including descriptive statistics and MANOVA, and coefficient alphas was reported for modified instruments in order to address reliability and validity of the instrument. The results indicated that three dimensions-intuitive, normative, and analytical-had a significant relationship affected by education among the three regions. The researcher suggests that the negotiators still need to be trained in body language, strategies, temper control, international manners, and customs. A better knowledge of negotiation should be helpful in understanding business and in realizing which negotiation styles are most appropriate for a particular country. The appropriate negotiation skills can bring more competitive advantages and benefits.
\end{abstract}

Keywords: Education, negotiation style, Greater Chinas

\section{Introduction and Background}

Training and education is important in negotiation, and for a trained negotiator, good results are the consequence of knowing when to follow to his/her instincts and when to employ negotiation theories or use a combination of them (Nardi, 2006). Nardi (2006) also indicated that a country is training in education systems are affected by culture and Schneider and Barsoux (2003) announced "culture and institutional configurations work interactively to create potential competitive advantage or disadvantage" (p. 8). As the economics within Greater China become more internally linked together, it becomes increasingly important to understand the nuances of each culture encompassed by this term. In recent history, China has been separated politically and economically, which has had a great influence on the development of the business climate of each area. The competing evaluations of the regions also highlight the role of ethnic and cultural influences in the development of business climates. Within these areas, the styles and skills relating to business negotiations have been greatly altered by the varied socio-political systems. The difference in value systems has imbued each one with a different view of foreign cultures. In conducting business, Taiwan typically follows American and Japanese practices, and Taiwan retains some connections with Japan, but in the academic world, it has also been influenced by America (Bray \& Qin, 2001). Hong Kong had been a British colony at the end of the twentieth century, and Hong Kong typically follows British practices. The characteristics in Hong Kong are different from China and Taiwan (Bray \& Qin, 2001). China has adopted the command economic system and communism since 1945 (Kemenade, 1998). As of social policies at that time were closely guided by the Soviet Union, much of the education system, and especially the university sector, was restructured along Soviet lines (Hayhoe, 1999). This continued until 1979, when Deng Xiaoping announced his "open door policy" (International Tax Review, 2007), resulting in China having more opportunities to contract with other countries. As the number of face-to-face negotiations dramatically increases, business negotiation strategies, styles, and agreements are becoming more important (Kumar, Markeset, \& Kumar, 2004). Numerous factors can affect the results of the negotiating process. A few of these include culture, personality, gender, experience, knowledge, and education of the parties involved in the 
negotiation process. How can one maintain the greatest advantage in negotiating, especially when faced by numerous people with different backgrounds? Obtaining information about the other parties, and being aware of their cultural differences becomes extremely helpful to negotiating effectively. No one should enter into any negotiations without preparation, because a lack of preparation could result in losing the idea. The cultural differences among Chinese living in Taiwan, Hong Kong, and Mainland China affect the internal and external business negotiations of Greater China. Considering the role of Greater China in international business, the knowledge of cultural differences among Chinese and its impact on business negotiations is incredibly important. There is a lot of literature comparing the negotiation styles of Chinese who live in Taiwan, Hong Kong, or China with foreigners, but there is very little comparing the negotiation styles of Chinese who live in Taiwan, Hong Kong, and China among themselves. To fill the gap, the focus of this study is on differences of educational systems and their effects on the negotiation styles of Chinese. The present research focuses on negotiations style comparison by education among Chinese in Taiwan, Hong Kong, and China to realize whether the three areas have differences on negotiation styles.

\section{Literature Review}

Greater China: During the past 20 years, international business and investment among the economic areas in East Asia, including three areas referred to as "Greater China," have intensified and contributed to the area's overall economic growth (Cui, 1998). The concept of "Greater China" is a sophisticated phenomenon, defined through scholarly studies that investigated Chinese subjects within the three economies, i.e. China (PRC), Hong Kong, and Taiwan (Wang \& Zhang, 2004; Hodson, 2003; Crawford, 2000; Ogden, 1998). From a political point of view, "Greater China" encompasses China, Taiwan, Hong Kong and Macao, though many citizens within these regions feel uncomfortable with the unity implied by the label (Ziegler, 1997). In some cases, "Greater China" includes Hong Kong, Taiwan, Macao, and at times, Singapore, but excludes China (Bjerke, 1999). The economic integration and growth among China (PRC), Hong Kong, and Taiwan have occurred so rapidly that the group of countries is referred to as the Chinese Economic Area (CEA), also known as Greater China (Cui, 1998). The term Chinese Context is also sometimes used to describe this economic region (Li \& Tsui, 2002). The most common name, Chinese Economic Area (CEA), usually refers to China, Hong Kong, and Taiwan but is often broadened to include Singapore, Macao, and other areas influenced by Chinese culture. In its narrowest sense, CEA only refers to Hong Kong, Taiwan, and coastal China, mainly Guangdong and the Fujian Province (Cui, 1998). For this study, Greater China is defined as Taiwan, China, and Hong Kong.

Culture: Differences in negotiating styles originate from the fact that every society places different degrees of importance on "relationship development, negotiating strategies, decision making methods, spatial and temporal orientations, contracting practices, and illicit behaviors such as bribery" (Acuff, 1997). Although Taiwan, Hong Kong, and Mainland China largely originate from similar cultures and shared ancestry, their negotiation styles have been greatly influenced by their different socio-political systems (Prasad \& Rumbaugh, 2003). Barbash and Taylor (1997) indicated that culture includes religion, gender, language, class, ethnicity, and sexual orientation. Since sub-cultures, cultures and super-cultures merge and evolve, while being less bounded than before; the idea of culture is more porous and varied than before (Barbash \& Taylor, 1997). "Culture is defined as a set of shared values and beliefs that characterize national, ethnic, moral and other group behavior" (Faure \& Sjostedt, 1993). One further definition of culture was put forth by Schein as a pattern of shared basic assumptions that a group learned as it solved its problems of external adaptation and internal integration, that has worked well enough to be considered valid and, therefore be taught to new members as the appropriate way to perceive, think, and feel with relation to those problems (Schein, 1997).

Negotiation: The negotiation process between the buyer and the seller is a very important matter (Neslin \& Greenhalgh, 1983), and achieving success in negotiation is one of the most challenging communicative tasks in business (Gilsdorf, 1997). In the broadest sense, negotiation is a process of communicating back and forth to discuss the issues to reach an agreement that is satisfactory to all parties involved (Foroughi, 1998; Gulbro \& Herbig, 1994). In 1994, Delivre's theoretical literature (as cited in Demers, 2002) indicated that: Negotiation is a process for managing disagreements with a view to achieving contractual satisfaction of needs. Negotiation is a process, that is, a method that consists of a number of steps. A method for managing disagreements, because the two parties could not initially agree to satisfy their needs to their mutual satisfaction. It is therefore desirable to achieve contractual satisfaction. (p. 35). Negotiation is a kind of 
social interaction for reaching an agreement for two or more parties, with different objectives or interests that they think are important (Manning \& Robertson, 2003; Fraser \& Zarkada-Fraser, 2002). Cross-cultural negotiations are more complicated due to cultural factors, environments, languages, communication styles, ideologies, and customs (Hoffmann, 2001; Mintu-Wimsatt \& Gassenheimer, 2000). When conducting international business strategic alliances, business negotiation and multilateral negotiations have become essential (Graham, Mintu, \& Rodgers, 1994).

Negotiation Process Model: Rubin and Brown (1975) indicated that the negotiation process model originated from the exchange theory set forth. This exchange theory is divided into three stages: the antecedent stage, the concurrent stage, and the consequent stage (Rubin \& Brown, 1975). The exchange theory was further revised to the negotiation process model by Graham in 1987. Graham (1987) introduced his seminal theory of the negotiation process model based on his qualitative and phenomenological studies of negotiation. This model identifies four major variables related to the negotiation process--negotiator characteristics, situational variables, process variables, and outcome phases. The major propositions in this theory are based on pre-negotiation planning and the preparation phase. These are all linked to the negotiators' characteristics such as gender, age, negotiation experience, and education, as well as situational constraints such as the level of competition and collaboration (Graham, 1987). The model developed by Graham depicting the direct and indirect relationships among concepts continues to be utilized and investigated (Peterson \& Lucas, 2001). Graham's theory is socially significant for addressing essential issues about steps that should be followed for a disciplined negotiation style. Additionally, it is useful for explaining and predicting the outcome of face-to-face negotiations. In the past few years, the theory has been adapted to show the effects of gender differences in negotiation styles for Americans and Canadians. Overall, Graham's theory has been used to examine the effect of gender, age, education, and experiences in negotiation with well-developed propositions and strong empirical support. Stuhlmacher and Walters (1999) conducted an empirical study of gender differences of people who are at least 14 years old from the United States and Canada in negotiation outcomes using a causal-comparative, quantitative design. The authors' literature review was thorough in its comparison of current theories concerning the effect of gender, the potential for successful task completion, and mode of communication employed. Empirical studies of homogeneity were reviewed which exposed the major gap and existing conflict regarding the overall effect of the gender of the opponent, relative power differences between negotiators, integrative potential of the task, and modes of communication. Due to this shortcoming, Stuhlmacher and Walters's study tested the proposition that males and females have a significant difference in negotiation outcomes because women receive less compensation from organizations. Overall, the results showed a significant difference between males and females in negotiation outcomes. It also suggested that the outcome of the negotiation for females in the workplace might be a factor in creating a "glass ceiling." This led to the researchers' conclusion that women may be worse negotiators or have difficulty employing the proper negotiation tactics. Despite these findings, Stuhlmacher and Walters cautioned that they combined the representatives and characteristics of the studies, and that the overall sample size was too small. In addition, their study excluded studies that employed abstract bargaining paradigms. In their conclusion, the researchers highlighted the following areas for future study: (a) the consideration of gender differences according to other dependent variables in negotiation, such as time and cost expended to resolve the conflict, and (b) an explanation of the more subjective reactions to negotiations including satisfaction, perceptions of one's opponent, and the willingness of both parties to engage in future negotiations.

Hall's High-Low Context Cultures: Hall (1976) introduced his theory of high-low context cultures based on his qualitative, phenomenological studies about communication styles. This theory stresses the influence of high-context cultures, defined as those, which rely primarily on non-verbal/informal communication; and low-context cultures, which rely on verbal/formal communication (Simintiras \& Thomas, 1998). Mintu-Wimsatt and Gassenheimer (2002) also indicated that the contexts of communication styles are embodied in high- and low-cultures. "Context variables such as individual backgrounds, associations, values and position in society need to be considered in order to comprehend the message" (Mintu-Wimsatt \& Gassenheimer, 2000, p. 1). In an empirical study that tested the theory's supposition, Cohen compared highand low-context cultures. Individuals from high-context cultures, like Japan, are "characterized as communal, face-saving, guarded in speech, preferring indirect to direct confrontation, and viewing history as living and relevant to decisions,' " while those from low-context cultures, like America, are "'characterized by their 
prioritization of directness, the use of language as information, and establishing the relevance of time to negotiations' " (as cited in Schehr \& Milovanovic, 1999). Cross-cultural studies like the one aforementioned are related to analyzing the effect of different elements including educational background, beliefs, art, morals, customs, laws, and economic (Evans, Hau, \& Sculli, 1989). Mintu-Wimsatt and Gassenheimer (2000) conducted an empirical study about cultural context in buyer-seller negotiations. They used a non-experimental, causal- comparative, quantitative design of industrial exporters from the United States and the Philippines. The literature review was thorough in comparing and contrasting theories about problem-solving approaches of both high and low context cultures. When empirical studies of buyer-seller negotiations were examined, the existing research revealed major differences in problem-solving approaches depending on gender and cultural background--i.e. high- or low -context culture. This resulted in Mintu-Wimsatt and Gassenheimer's study that tested Hill's proposition of high (HC) and low culture (LC). The result indicated that cultural context does not play an important role between gender and problem-solving approaches. In the same culture of HC or LC environment, there were no obvious differences between males and females in negotiations, and gender did not appear to influence cooperative problem solving. The results also suggested that a high-context culture decreases the positive influences of negotiation while using a problem-solving approach. This led to the conclusion that HC negotiators rely more heavily on cooperative problem solving than LC negotiators. Mintu-Wimsatt and Gassenheimer heralded the results of the study in their support for the notion that a better understanding of cultural context and demographic characteristics can enhance negotiation efforts and improve their overall results.

Janosik's Cross-Cultural Negotiation Model: Janosik (1987) introduced his seminal theory of cross-cultural negotiation research based on his qualitative, phenomenological studies to find the relationship between culture and negotiation. The theory also provides that no matter which approach to negotiation be applied, it is still important to understand individual variations in negotiation styles when parties attempt to negotiate cross-culturally. Several subsequent empirical studies by Osman-Gani and Tan led to refinement of the theory. Through these studies, the researchers verified the propositions about different negotiation styles in different cultures. Lately, the theory has been adapted to fit cross-cultural business negotiations involving Asian managers. In one study, Osman-Gani and Tan (2002) conducted an exploratory quantitative study of cross-cultural impacts on negotiation styles of Chinese, Malay, and Indian managers living in Singapore. Their literature review comprehensively examined research relating to the effect of culture on the process of negotiation. Noting the shortcomings of existing research, Osman-Gani and Tan designed their study to test Janesik's propositions with regard to cross-cultural negotiation. These negotiation styles were defined by Osman-Gani and Tan as follows: A factual style identifies facts in an unemotional manner, pays attention to details and all statements made during a negotiation, and places much importance on proof and facts as related to experience. An intuitive person is warm and animated when making statements, flexible and creative during negotiations, fluid and able to adapt to changing subjects and situations, and imaginative in projecting into the future. A normal person considers and weights facts according to a set of personal values; this person uses all the tools at his or her disposal, such as emotions, status, authority, and rewards, to come up with the best bargain. The analytical negotiator is strongly logical, tries to find cause-and-effect in all issues, and likes to weigh pros and cons thoroughly. (p. 825). The study's value lies in its ability to help people understand the similarity of negotiation styles among Chinese, Malay, and Indian managers in Singapore. Osman-Gani and Tan's analysis of the results did not reveal a large difference between the three groups in their negotiations when comparing intuitive, normative, analytical, and factual styles. These findings led to the researchers' conclusion that Chinese, Malay, and Indian managers in Singapore have no significant differences in negotiation styles.

\section{Methodology}

The study employed a non-experimental, quantitative research design to analyze educational system differences among Chinese people living in Taiwan, Hong Kong, and China. The research design used was causal-comparative (exploratory) and correlational (explanatory), and was intended to examine, describe, and explore the differences and similarities of various negotiation styles in relation to the cultural differences in the three distinct geographic regions of Greater China. The research model and hypotheses are as follows: 
Figure 1: Research Model

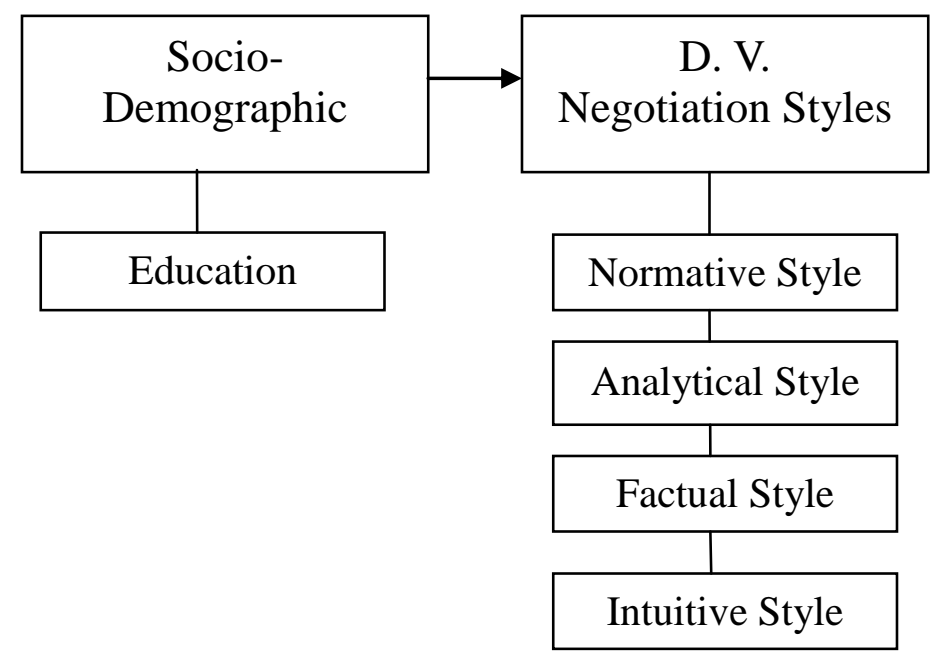

H1. There is a significant relationship between the normative negotiation style and education of managers or negotiators of public companies in the three regions.

$\mathrm{H} 2$. There is a significant relationship between the analytical negotiation style and education of managers or negotiators of public companies in the three regions.

H3. There is a significant relationship between the factual negotiation style and education of managers or negotiators of public companies in the three regions.

H4. There is a significant relationship between the intuitive negotiation style and education of managers or negotiators of public companies in the three regions.

The dependent variables of the model employed in this research are the four negotiation styles including factual negotiation, intuitive negotiation, normative negotiation, and analytical negotiation developed by Casse and Deol (1985). There are 8 questions designed to examine each negotiation style (factual negotiation style, intuitive negotiation style, normative negotiation style, and analytical negotiation style) that are analyzed on the five-point Likert scale. There are five options for each statement: 5. "Always" (around 100\% of the time); 4. "Often" (around 75\% of the time); 3. "Occasionally" (around 50\% of the time); 2. "Seldom" (around 25\% of the time); 1. "Never" (around 0\% of the time). In total, there are 32 questions for the four negotiation styles. The independent variable is gender. For the data collection of demographic variables, the participants are provides the questions as follows. Education (as a nominal variable): 1= "High School Diploma or Equivalent"; 2= "Associate Degree"; 3= "Bachelor Degree"; 4= "Graduate Degree". Religion (as a nominal variable): 1= "Buddhist"; 2= "Christian"; 3= "Moslem"; 4= "Others". Gender is defined as a dichotomous variable ( $1=$ Male; $2=$ Female). Age is defined as a nominal variable $(1=$ under $35 ; 2=35-45 ; 3=$ 46-55; $4=$ over 55). Region of birth: $1=$ "Taiwan"; $2=$ "Hong Kong"; $3=$ "Mainland China". For this study, the accessible population was chosen from public companies listed under the Taiwan Stock Exchange Corporation (TSEC), Hong Kong Exchanges and Clearing Limited (HKEx), Shenzhen Stock Exchange (SSE) and Shanghai Stock Exchange in China. There were 700 listed companies in the Taiwan Security Exchange Corporation (TSEC), and all listed companies were classified into eight sectors, including cement and ceramics, foods, plastics and chemical, textiles, electric \& machinery, paper and pulp, construction, and financial. There were 911 listed companies on the Hong Kong Exchanges and Clearing Limited (HKEx), and all companies were classified into six sectors, including financials, utilities, real estate, industries, hotels, and others. In China, there were 585 listed companies (including A stock: 530 companies and B Stock: 55 companies) in the Shenzhen Stock Exchange (SSE), and all companies are classified into six sectors, including industry, business, financials, real estate, utilities, and others. There were 872 listed companies (including A stock: 820 companies and B Stock: 52 companies) in the Shanghai Stock Exchange, and all companies were classified into five sectors, including industry, business, real estate, utilities, and others. In total, there were 3,068 listed public companies in Taiwan, Hong Kong, and China. Any company listed on these markets had the potential to be included in this study. 
In order to avoid sampling errors, the population was collected from different sectors of stock markets in the three regions. A random sample was taken from each of these sectors through a stratified random sampling. Overall, this method for determining a sample population is more accurate than purely random sampling, further it allows the researcher to select a sample that accurately reflects the diverse sectors and characteristic patterns in the desired population (Wallen \& Fraenkel, 2001). This research method is useful in that it allows a small but carefully selected data pool to provide insight into the more general trends of a larger population. The principal characteristic of probability sampling is that every member or individual has an equal probability of being selected from the population as the sample (Ary, Jacobs, \& Razavier, 1996). This is also the reason why the researcher used a probability-sampling plan in this study that allowed, through use of inferential statistics, the researcher to evaluate the extent to which the findings were likely to be different from what they would have been because of investigating the whole population (Ary, Jacobs, \& Razavier, 1996). Under ideal circumstances, researchers could conduct studies that sample entire populations with $100 \%$ participant rates. Due to practicalities, the researcher was forced, for a variety of reasons, to find a representative sample size. Hair, Anderson, Tatham, \& Black (1998) recommended that the minimum sample size is at least five times as many as the observed variables for factor analysis. Gay and Airasian (2000) suggested that if the population is over 5,000, a sample size of 400 should be adequate. Wallen \& Fraenkel (2001) indicated that the best sample size should be as large as researchers can acquire with a reasonable expense of time and energy. Larger sample sizes are more likely to represent the target population (Grossnickle \& Raskin, 2001). In the research, data was collected using an online survey technique. Sheehan (2001) reported that the average response rate of online survey is $36.83 \%$. Therefore, a large number of the initial e-mail invitations for this study were sent out to ensure a large enough number of online survey responses were obtained. The number of listed companies in the stock markets in Taiwan, Hong Kong, and China was 3,068. With an accessible population of 9,204 including CEOs and sales and purchase managers, the desired sample size was 4,605 in order to increase generalization and reduce sampling errors, as suggested by Wallen, Fraenkel, Grossnickle, and Raskin in 2001. To obtain the desired initial sample size of $4,605,1,535$ companies were chosen, and each company's CEOs and sales and purchase managers were randomly selected from listed companies of stock markets in Taiwan, Hong Kong, and China. Invitation e-mails were sent to 4,605 participants. All information, such as the names of CEOs and sales and purchase managers, and e-mail addresses of listed companies were obtained through the website of the Taiwan Stock Exchange Corporation (TSEC), Hong Kong Exchanges and Clearing Limited (HKEx), Shenzhen Stock Exchange (SSE), and Shanghai Stock Exchange. The survey was accessible on the Internet without direct contact with the researcher. The CEOs and sales and purchase managers of the sample population were invited to participate via an e-mail that explained the research and included a link to the survey website. The questionnaire was posted on the website, "www.my3q.com" in English, traditional Chinese, and simplified Chinese. The researcher asked respondents to return the surveys within 30 days by sending an e-mail to "www.my3q.com" website.

Three hundred and fifty companies were considered from the 700 listed companies on the Taiwan Stock Exchange Corporation. Three e-mails were sent, one of each to each company's CEOs and sales and purchase managers. There were 1050 potential respondents in total. The number of companies that were considered from the 911 listed on the Hong Kong Exchanges and Clearing Limited (HKEx) were 456. The CEOs and sales and purchase managers of each company were contacted by e-mail. The total number of potential respondents for this study from Hong Kong was 1,368. Two hundred and sixty-five companies were considered from the 530 listed on the Shenzhen Stock Exchange (SSE) of A Stock. There were 795 subjects from the Shenzhen Stock Exchange (SSE) of A Stock. Twenty-eight companies were considered from the 55 listed companies in the Shenzhen Stock Exchange (SSE) of B Stock. The CEOs and sales and purchase managers of each company were contacted by e-mail. This sample had 84 subjects. Four hundred and ten companies were considered from the 820 listed on the Shanghai Stock Exchange of a Stock. The CEOs and sales and purchase managers were contacted by e-mail. There were 1,230 subjects for this study from the Shanghai Stock Exchange of A Stock. Twenty-six companies were considered from the 52 listed in the Shanghai Stock Exchange of B Stock. The CEOs and sales and purchase managers of each company were contacted by e-mail. There were 78 subjects from the Shanghai Stock Exchange of B Stock. The Statistics Package of Social Science (SPSS) for Windows version 13.0 was used to conduct data analyses on collected data. A variety of statistical measures were used, including descriptive statistics and MANOVA. SPSS was also 
utilized to report coefficient alphas for modified instruments in order to address reliability and validity of the instrument.

\section{Results}

In this study, 4,605 invitations were e-mailed to public companies' CEOs and sales and purchase managers in Taiwan, Hong Kong, and China by a stratified probability-sampling plan. A hyper-link to the survey web site was provided on each invitation e-mail. Participants who chose to take part in the study were directed to the survey. Data collection lasted for one month, and 860 questionnaires were returned. However, 251 questionnaires were incomplete or invalid. There were 168 usable questionnaires from Taiwan; 179 from Hong Kong, and 262 from China. 609 usable questionnaires were obtained for data analysis.

Reliability Analysis: The internal consistency reliability was measured by using Cronbach's coefficient $a$ according to the mean or average correlation of each item with every other item. Initially, the internal consistency reliability of the individualist/collectivist characteristics and four negotiation styles were assessed and the reliability coefficients of each subscale as follows: 1 ) individualist/collectivist characteristics (10 items); Cronbach $\alpha=0.74 ; 2$ ) analytical negotiation styles (18 items): Cronbach $\alpha=0.87 ; 3$ ) normative negotiation styles (18 items): Cronbach $\alpha=0.75$; 4) factual negotiation styles (18 items): Cronbach $\alpha=0.85$; a nd 5) intuitive negotiation styles (18 items): Cronbach $\alpha=0.82$. Lin (2006) states that Cronbach's $a$ value in basic research should be at least 0.80 . For higher internal consistency reliability, four questions were removed from the questionnaire of individualist/collectivist characteristics, and the Cronbach's $a$ value became 0.81 . Eight questions were removed from the questionnaire of each negotiation style. The analytical negotiation style Cronbach's $a$ value became 0.92; the questionnaire of normative negotiation style Cronbach's $a$ value rose to 0.87 ; the Cronbach's $a$ value increased to 0.88 ; and the questionnaire of intuitive negotiation style Cronbach's $a$ value became 0.86 .

Exploratory Factor Analysis: The Kaiser-Meyer-Olkin (KMO) test and Bartlett's test had to be examined before performing factor analysis. According to Lin (2006), a KMO value larger than 0.50 is acceptable, and in 2005, Leech, Barrett, and Morgan found that Bartlett's test should be significant. The KMO value for the variables used in the study was 0.54 , and Bartlett's test was significant, which means all negotiation styles in this study were sufficient for social science research and factor analysis, and could therefore be performed. These items were categorized into four negotiation styles. Each negotiation style was combined with several items that participants needed to respond to in the questionnaire. Goodwin and Goodwin (1999) indicated that if a factor loading is less than 0.30 , the variable should not be considered a part of the factor. All of the factor loadings in the study were above 0.30 , indicating that the construct validity was acceptable. Among the 609 respondents, $453(74.4 \%)$ were male and 156 (25.6\%) were female. In this study, 39 respondents (6.4\%) held a high school diploma or equivalent; 23 respondents (3.8\%) had an associate degree; 319 respondents $(52.4 \%)$ were college or university graduates; and 228 respondents (37.4\%) had a graduate degree. In terms of religion, 165 respondents (27.1\%) were Buddhist; 67 (11.0\%) were Christian; 38 (6.2\%) were Muslim; and 339 (55.7\%) were others. The largest number, nearly a third, 168 (27.6\%) of respondents were from Taiwan; 179 (29.4\%) were from Hong Kong; and 262 (43.0\%) were from China. Respondents' age ranged from 35 to 45 years old. There were $169(27.7 \%)$ respondents under 35 years old; $258(42.4 \%)$ between 35 and 45 years old; $132(21.7 \%)$ from 46 to 55 years old; and 50 (8.2\%) who were older than 55 . The value of Wilks' Lambda was $F=2.859(p<0.001)$, and that MANOVA for the interaction of education and region was significant. The Test of Between-Subject Effect, as shown in Table 1, indicated that the interaction between the education and regions was a significant factor $(p<0.05)$ in affecting the normative, analytical and intuitive negotiation styles but the interaction between the education and regions was not a significant factor $(p>0.05)$ in affecting the factual negotiation style. 
Table 1: Test of Between-Subject Effect of Education Level

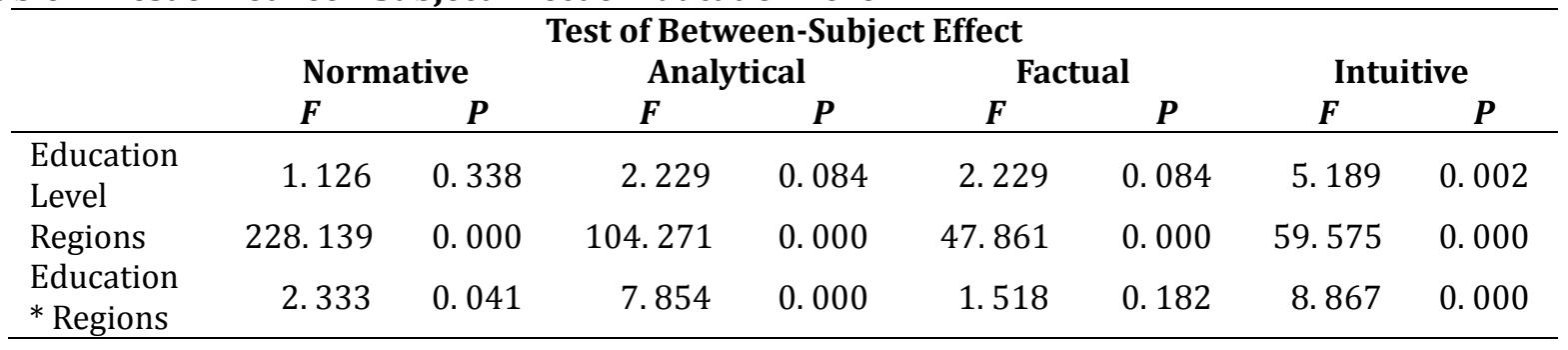

H1. There is a significant relationship between the Normative negotiation style and education of managers or negotiators of public companies in the three regions.

As Table 2 presents the results of the test on the normative negotiation style, the education in the high school diploma or equivalent group was a significant factor affecting the normative negotiation style, and the value of Wilks' Lambda was $F=84.377, p<0.001$, and the value of the Test of Between-Subject Effect was $F=64.037$, $p<0.001$. The education in multi-variable analysis in the associate degree group was a significant factor affecting the normative negotiation style, and the value of Wilks' Lambda was $F=13.640, p<0.001$, and the value of the Test of Between-Subject Effect was $F=10.377, p<0.001$. The education in multi-variable analysis in the bachelor degree group was a significant factor affecting the normative negotiation style, and the value of Wilks' Lambda was $F=149.025, p<0.001$, and the value of the Test of Between-Subject Effect was $F=$ $244.164, p<0.001$. The education in multi-variable analysis in the graduate degree group was a significant factor affecting the normative negotiation style, and the value of Wilks' Lambda was $F=122.005, p<0.001$, and the value of the Test of Between-Subject Effect was $F=229.519, p<0.001$.

Table 2: Multivariate Test and Test of Between-Subject Effect on Normative Negotiation Style for Education

\begin{tabular}{|c|c|c|c|c|c|c|}
\hline \multirow[t]{2}{*}{$\begin{array}{l}\text { Dependent } \\
\text { Variable }\end{array}$} & \multirow[t]{2}{*}{ Education } & \multicolumn{3}{|c|}{$\begin{array}{l}\text { Multivariate Test } \\
\text { (Wilks' Lambda) }\end{array}$} & \multicolumn{2}{|c|}{$\begin{array}{l}\text { Test of Between- } \\
\text { Subject Effect }\end{array}$} \\
\hline & & $F$ & df & $\boldsymbol{P}$ & $\boldsymbol{F}$ & $\boldsymbol{P}$ \\
\hline \multirow[t]{4}{*}{ Normative } & $\begin{array}{l}\text { High School Diploma or } \\
\text { Equivalent }\end{array}$ & 84.377 & 8. 000 & 0.000 & 307.309 & 0.000 \\
\hline & Associate Degree & 13.640 & 4. 000 & 0.000 & 10. 377 & 0.004 \\
\hline & Bachelor Degree & 149.025 & 8. 000 & 0.000 & 244.164 & 0.000 \\
\hline & Graduate Degree & 122.005 & 8.000 & 0.000 & 229.519 & 0.000 \\
\hline
\end{tabular}

Total mean scores of education for each region, based on the normative negotiation style, were as follows: high school diploma or equivalent (Taiwan $=4.300$, Hong Kong $=2.441$, and China $=3.700$ ), associate degree (Taiwan $=3.900$ and Hong Kong $=2.883$ ), bachelor degree $($ Taiwan $=4.184$, Hong Kong $=2.783$, and China $=$ 3.764 ) and graduate degree (Taiwan $=4.134$, Hong Kong $=2.745$, and China $=3.676$ ) as shown in Table 3. As for normative negotiation style, the mean difference of the Post Hoc Test among subjects at all level groups of education (high school diploma or equivalent group, bachelor degree and graduate degree), the Taiwan group had the highest significant value, as shown in Table 4. It means that negotiators from Taiwan with high school diploma or equivalent, bachelor and graduate degrees prefer to employ the intuitive negotiation style more so than negotiators from China and Hong Kong with the same credentials. Therefore, it can be concluded that the interaction between education and regions is a significant variable affecting the normative negotiation style of business negotiators of the three regions.

H2. There is a significant relationship between the analytical negotiation style and education of managers or negotiators of public companies in the three regions.

Table 5 presents the results of the test on the analytical negotiation style. The test found that the education in multi-variable analysis for the high school diploma or equivalent group was a significant factor affecting the analytical negotiation style, and the value of Wilks' Lambda was $F=84.377, p<0.001$, and the value of the Test of Between-Subject Effect was $F=60.449, p<0.001$. The education in multi-variable analysis in the associate degree group was a significant factor affecting the analytical negotiation style, and the value of Wilks' Lambda 
was $F=13.640, p<0.001$, and the value of the Test of Between-Subject Effect was $F=7.242, p<0.05$. The education in multi-variable analysis in the bachelor degree group was a significant factor affecting the analytical negotiation style, and the value of Wilks' Lambda was $F=149.025, p<0.001$, and the value of the Test of Between-Subject Effect was $F=214.536, p<0.001$. The education in the graduate degree group was a significant factor affecting the analytical negotiation style, and the value of Wilks' Lambda was $F=122.005$, $p<0.001$, and the value of the Test of Between-Subject Effect was $F=82.788, p<0.001$.

Table 3: Estimated Marginal Means on Normative Negotiation Style for Education

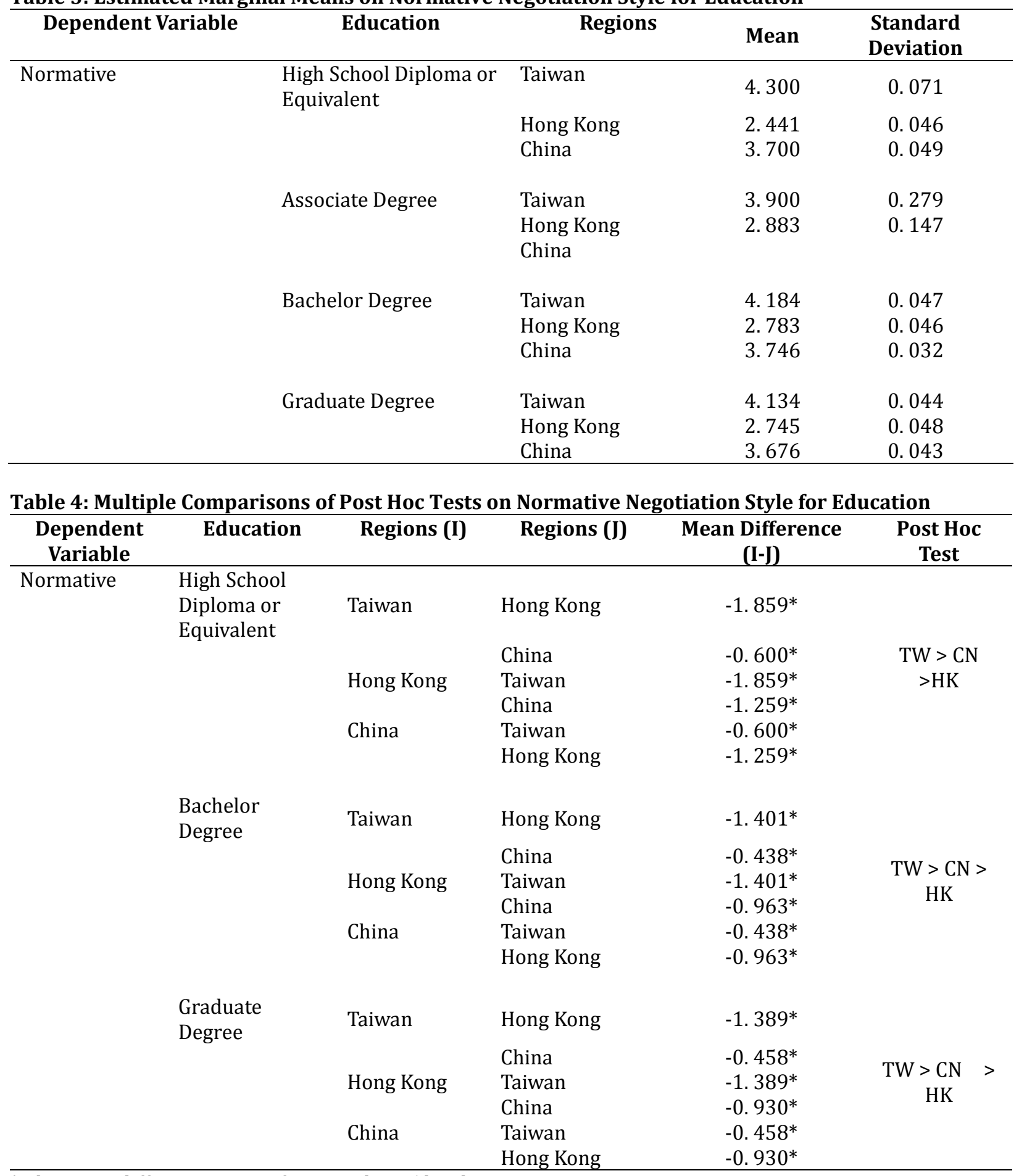

\footnotetext{
* The mean difference is significant at the .05 level.
} 
Table 5: Multivariate Test and Test of Between-Subject Effect on Analytical Negotiation Style for Education

\begin{tabular}{llrcrrr}
$\begin{array}{c}\text { Dependent } \\
\text { Variable }\end{array}$ & \multicolumn{1}{c}{ Education } & \multicolumn{2}{c}{$\begin{array}{c}\text { Multivariate Test } \\
\text { (Wilks' Lambda) }\end{array}$} & \multicolumn{2}{c}{ Test of Between- } \\
& & $\boldsymbol{F}$ & Subject Effect \\
df & $\boldsymbol{P}$ & \multicolumn{1}{c}{$\boldsymbol{F}$} & $\boldsymbol{P}$ \\
\hline Analytical & High School Diploma or & 84.377 & 8.000 & 0.000 & 60.449 & 0.000 \\
& Equivalent & 13.640 & 4.000 & 0.000 & 7.242 & 0.014 \\
& Associate Degree & 149.025 & 8.000 & 0.000 & 214.536 & 0.000 \\
& Bachelor Degree & 122.005 & 8.000 & 0.000 & 82.788 & 0.000 \\
\hline
\end{tabular}

Total mean scores of education for each region, based on the analytical negotiation style, were as follows: high school diploma or equivalent (Taiwan $=2.900$, Hong Kong $=3.741$, and China $=4.160$ ), associate degree (Taiwan $=2.600$ and Hong Kong $=3.422$ ), bachelor degree (Taiwan $=2.638$, Hong Kong $=3.545$, and China $=$ 4.027) and graduate degree (Taiwan $=2.830$, Hong Kong $=3.742$, and China $=3.690$ ) as shown in Table 6 .

Table 6: Estimated Marginal Means on Analytical Negotiation Style for Education

\begin{tabular}{llllc}
\hline Dependent Variable & \multicolumn{1}{c}{ Education } & \multicolumn{1}{c}{ Regions } & Mean & $\begin{array}{c}\text { Standard } \\
\text { Deviation }\end{array}$ \\
\cline { 3 - 5 } Analytical & High School Diploma or & Taiwan & 2.900 & 0.095 \\
& Equivalent & Hong Kong & 3.741 & 0.061 \\
& & China & 4.160 & 0.065 \\
& Associate Degree & Taiwan & 2.600 & 0.270 \\
& \multirow{3}{*}{ Bachelor Degree } & Hong Kong & 3.422 & 0.142 \\
& & Taiwan & 2.638 & 0.055 \\
& Gong Kong & 3.545 & 0.055 \\
& Graduate Degree & China & 4.027 & 0.038 \\
& & Taiwan & 2.830 & 0.056 \\
& & Hong Kong & 3.742 & 0.061 \\
& & China & 3.690 & 0.054 \\
\hline
\end{tabular}

As for the analytical negotiation style, the mean difference of the Post Hoc Test of the high school diploma or equivalent group and the bachelor degree group, the China group showed the highest significant value but as for the graduate degree group, the Hong Kong group had the highest significant value as shown in Table 7. It means that negotiators from China with the education of high school diploma or equivalent and bachelor degree prefer to employ the intuitive negotiation style more so than negotiators from Taiwan and Hong Kong, and negotiators from Hong Kong with the education of graduate degree mostly employ the intuitive negotiation style more so than negotiators from China and Taiwan. Therefore, it can be concluded that the interaction between education and regions is a significant variable affecting the analytical negotiation style of business negotiators of the three regions.

H3. There is a significant relationship between the factual negotiation style and education of managers or negotiators of public companies in the three regions.

The interaction between education and regions is not a significant variable affecting the factual negotiation style of business negotiators. That is, the factual negotiation style of business people in the three regions does not depend on the differences in education among the three regions (Table 1).

H4. There is a significant relationship between the intuitive negotiation style and education of managers or negotiators of public companies in the three regions.

Table 8 presents the results of the test on the intuitive negotiation style. Here the education in multi-variable analysis for the high school diploma or equivalent group was a significant factor affecting the intuitive 
negotiation style. The value of Wilks' Lambda was $F=84.377, p<0.001$, and the value of the Test of Between-Subject Effect was $F=13.254, p<0.001$.

Table 7: Multiple Comparisons of Post Hoc Tests on Analytical Negotiation Style for Education

\begin{tabular}{|c|c|c|c|c|c|}
\hline $\begin{array}{l}\text { Dependent } \\
\text { Variable }\end{array}$ & Education & Regions (I) & Regions (J) & $\begin{array}{c}\text { Mean Difference } \\
\text { (I-J) }\end{array}$ & $\begin{array}{l}\text { Post Hoc } \\
\text { Test }\end{array}$ \\
\hline \multirow[t]{20}{*}{ Analytical } & High School & & & & \\
\hline & Diploma or & Taiwan & Hong Kong & $-0.841^{*}$ & \\
\hline & Equivalent & & & & \\
\hline & & & China & $-1.260^{*}$ & $\mathrm{CN}>\mathrm{TW}$ \\
\hline & & Hong Kong & Taiwan & $-0.841 *$ & $>\mathrm{HK}$ \\
\hline & & & China & $-0.419 *$ & \\
\hline & & China & Taiwan & $-1.260^{*}$ & \\
\hline & & & Hong Kong & $-0.419 *$ & \\
\hline & Bachelor Degree & Taiwan & Hong Kong & $-0.907^{*}$ & \\
\hline & & & China & $-1.389 *$ & \\
\hline & & Hong Kong & Taiwan & $-0.907^{*}$ & $\mathrm{CN}>\mathrm{HK}$ \\
\hline & & & China & $-0.483^{*}$ & $>\mathrm{TW}$ \\
\hline & & China & Taiwan & $-1.389 *$ & \\
\hline & & & Hong Kong & $-0.483^{*}$ & \\
\hline & Graduate Degree & Taiwan & Hong Kong & $-0.912 *$ & \\
\hline & & & China & $-0.860 *$ & \\
\hline & & Hong Kong & Taiwan & $-0.912 *$ & $\mathrm{HK}>\mathrm{CN}$ \\
\hline & & & China & - 0. 0528* & $>\mathrm{TW}$ \\
\hline & & China & Taiwan & $-0.860^{*}$ & \\
\hline & & & Hong Kong & $-0.052 *$ & \\
\hline
\end{tabular}

* The mean difference is significant at the .05 level.

The education in multi-variable analysis in the associate degree group was a significant factor affecting the intuitive negotiation style, and the value of Wilks' Lambda was $F=13.640, p<0.001$, and the value of the Test of Between-Subject Effect was $F=20.384, p<0.001$. The education in multi-variable analysis in the bachelor degree group was a significant factor affecting the intuitive negotiation style, and the value of Wilks' Lambda was $F=149.025, p<0.001$, and the value of the Test of Between-Subject Effect was $F=121.524, p<0.001$. The education in multi-variable analysis in the graduate degree group was a significant factor affecting the intuitive negotiation style, and the value of Wilks' Lambda was $F=122.005, p<0.001$, and the value of the Test of Between-Subject Effect was $F=111.698, p<0.001$.

Table 8: Multivariate Test and Test of Between-Subject Effect on Intuitive Negotiation Style for Education

\begin{tabular}{llrccrc}
$\begin{array}{c}\text { Dependent } \\
\text { Variable }\end{array}$ & \multicolumn{1}{c}{ Education } & \multicolumn{2}{c}{$\begin{array}{c}\text { Multivariate Test } \\
\text { (Wilks' Lambda) }\end{array}$} & \multicolumn{2}{c}{$\begin{array}{c}\text { Test of Between- } \\
\text { Subject Effect }\end{array}$} \\
& & $\boldsymbol{F}$ & df & $\boldsymbol{P}$ & $\boldsymbol{F}$ & $\boldsymbol{P}$ \\
\hline Intuitive & High School Diploma or & 84.377 & 8.000 & 0.000 & 13.254 & 0.000 \\
& Equivalent & 13.640 & 4.000 & 0.000 & 20.384 & 0.000 \\
& Associate Degree & 149.025 & 8.000 & 0.000 & 121.542 & 0.000 \\
& Bachelor Degree & 122.005 & 8.000 & 0.000 & 111.698 & 0.000 \\
\hline
\end{tabular}

Total mean scores of education for each region, based on the intuitive negotiation style, were as follows: high school diploma or equivalent (Taiwan $=2.900$, Hong Kong $=3.612$, and China $=3.020$ ), associate degree $($ Taiwan $=4.200$ and Hong Kong $=3.400)$, bachelor degree $($ Taiwan $=3.714$, Hong Kong $=3.386$, and China $=$ 2.878 ) and graduate degree (Taiwan $=3.624$, Hong Kong $=3.406$, and China $=2.792$ ) as shown in Table 9. 
Table 9: Estimated Marginal Means on Intuitive Negotiation Style for Education

\begin{tabular}{lllcc}
$\begin{array}{c}\text { Dependent } \\
\text { Variable }\end{array}$ & \multicolumn{1}{c}{ Education } & \multicolumn{1}{c}{ Regions } & Mean & $\begin{array}{c}\text { Standard } \\
\text { Deviation }\end{array}$ \\
\hline Intuitive & High School Diploma or & Taiwan & 2.900 & 0.144 \\
& Equivalent & Hong Kong & 3.612 & 0.093 \\
& & China & 3.020 & 0.099 \\
& Associate Degree & Taiwan & 4.200 & 0.157 \\
& Bachelor Degree & Hong Kong & 3.400 & 0.083 \\
& & Taiwan & 3.714 & 0.046 \\
& Hong Kong & 3.386 & 0.046 \\
& Graduate Degree & China & 2.878 & 0.032 \\
& & Taiwan & 3.624 & 0.041 \\
& Hong Kong & 3.406 & 0.045 \\
& China & 2.792 & 0.040 \\
\hline
\end{tabular}

Table 10: Multiple Comparisons of Post Hoc Tests on Intuitive Negotiation Style for Education

\begin{tabular}{|c|c|c|c|c|c|}
\hline $\begin{array}{c}\text { Dependent } \\
\text { Variable }\end{array}$ & Education & Regions (I) & Regions (J) & $\begin{array}{c}\text { Mean } \\
\text { Difference (I-J) }\end{array}$ & Post Hoc Test \\
\hline \multirow[t]{18}{*}{ Intuitive } & $\begin{array}{l}\text { High School } \\
\text { Diploma or } \\
\text { Equivalent }\end{array}$ & Taiwan & Hong Kong & $-0.712^{*}$ & \\
\hline & & & China & $-0.120^{*}$ & $\mathrm{HK}>\mathrm{CN}>$ \\
\hline & & Hong Kong & Taiwan & $-0.712^{*}$ & TW \\
\hline & & & China & $-0.592^{*}$ & \\
\hline & & China & Taiwan & $-0.120^{*}$ & \\
\hline & & & Hong Kong & $-0.592 *$ & \\
\hline & $\begin{array}{l}\text { Bachelor } \\
\text { Degree }\end{array}$ & Taiwan & Hong Kong & $-0.329^{*}$ & \\
\hline & & & China & $-0.837^{*}$ & \\
\hline & & Hong Kong & Taiwan & $-0.329 *$ & $\mathrm{TW}>\mathrm{HK}>\mathrm{CN}$ \\
\hline & & & China & $-0.508^{*}$ & \\
\hline & & China & Taiwan & $-0.837^{*}$ & \\
\hline & & & Hong Kong & $-0.508^{*}$ & \\
\hline & $\begin{array}{l}\text { Graduate } \\
\text { Degree }\end{array}$ & Taiwan & Hong Kong & $-0.218^{*}$ & \\
\hline & & & China & $-0.833^{*}$ & \\
\hline & & Hong Kong & Taiwan & $-0.218^{*}$ & $\mathrm{TW}>\mathrm{HK}>\mathrm{CN}$ \\
\hline & & & China & $-0.615^{*}$ & \\
\hline & & China & Taiwan & $-0.833^{*}$ & \\
\hline & & & Hong Kong & $-0.615^{*}$ & \\
\hline
\end{tabular}

* The mean difference is significant at the .05 level.

As for intuitive negotiation style, the mean difference of the Post Hoc Test for the high school diploma or equivalent groups, the Hong Kong group had the highest significant value; as for the bachelor and graduate degree groups, the Taiwan group had the highest significant value (Table 10). It means that negotiators from Hong Kong who have a high school diploma or equivalent prefer to employ the intuitive negotiation style more so than negotiators from China and Taiwan, and negotiators from Taiwan with the education of bachelor and graduate degrees mostly employ the intuitive negotiation style as opposed to negotiators from Hong Kong and China. Therefore, it can be concluded that the interaction between education and regions is a significant variable affecting the intuitive negotiation style of business negotiators of the three regions.

Discussion: The results of this study revealed significant differences $(p<0.05)$ of the intersection of Test of Between-Subject Effect of education among the three regions on intuitive, normative, and analytical 
negotiation styles, but there was no significant difference $(p>0.05)$ on factual negotiation style among managers and negotiators from Taiwan, Hong Kong, and China. The intuitive negotiation style was correlated with education for the subjects in the study. At the high school diploma or equivalent level on intuitive negotiation style, Hong Kong negotiators had the highest preference to employ the intuitive negotiation style compared to negotiators from China and Taiwan. At the bachelor and graduate degree levels, Taiwan negotiators had the highest preference to employ the intuitive negotiation style compared to negotiators from Hong Kong and China. The normative negotiation style was correlated with education for the subjects in the study of Taiwan negotiators. At the all levels (high school diploma or equivalent, bachelor and graduate degrees), Taiwan negotiators had the highest preference to employ the normative negotiation style compared to negotiators from China and Hong Kong. The analytical negotiation style had a significant negative correlation $(B=-0.104)$ with education for the subjects of the regression model in this study. China negotiators from all educational levels (high school diploma or equivalent, bachelor and graduate degrees) had the highest preference to employ the analytical negotiation style compared to negotiators from China and Taiwan. Negotiators from Taiwan with a bachelor or graduate degree mostly employ the intuitive negotiation style, and with a high school diploma or equivalent, bachelor or graduate degree prefer to employ the intuitive negotiation style. Negotiators from Hong Kong with a high school diploma or equivalent prefer to employ the intuitive negotiation style, and with a graduate degree mostly employ the intuitive negotiation style. Negotiators from China with a high school diploma or equivalent or bachelor degree prefer to employ the intuitive negotiation style. During the time that Taiwan was a colony of Japan, Taiwan's educational system was adopted from the Japanese educational model (Tsurumi, 1984). Bray and Qin (2001) indicated that Taiwan's subsequent economic prosperity led to the expansion of higher education, and many scholars had received their higher education in the USA or Japan. Taiwan retains some connections with Japan, but its academic world has also been influenced by America (Bray \& Qin, 2001). In China, Russian was the dominant foreign language during the initial years of the People's Republic (Bray \& Qin, 2001). Because social policies at that time were closely guided by the Soviet Union, much of the education system, especially the university sector, was restructured along Soviet lines (Hayhoe, 1999). Gu (2001) indicated that "China is a socialist country guided by the thought of Karl Marx and Mao Zedong" (p. 242), while Taiwan and Hong Kong had never stressed Marxism and Maoism (Bray \& Qin, 2001). None of the respondents from China had an associate degree. Mou (2005) stated that only 164 of 1,277 institutes offer associate diplomas. Duan (2003) indicated that while there is a need for a two or three-year pre-bachelor system to meet the demands of economic development in China, there are too few of the colleges in proportion to China's population. This may explain why there are no respondents from China with an associate degree.

\section{Conclusion}

The researcher suggests that the negotiators still need to be trained in body language, strategies, temper control, international manners, and customs. A better knowledge of negotiation should be helpful in understanding business and in realizing which negotiation styles are most appropriate for a particular country. The appropriate negotiation skills can bring more competitive advantages and benefits. Negotiators should create a database about negotiation knowledge that can be applied in different countries. The researcher also suggests that further training and drilling are required for negotiators, and that negotiators should focus on a culture's specific requirements rather than general principles. Although the strategies would be costly in the short-term, company owners who realize the benefits of negotiation stand to gain advantages that are more competitive in the long term.

Recommendation: The findings were limited to the public companies, and was constrained by person-power, financial resources, and time; therefore the study adopted only a quantitative research method and employed a self-reporting questionnaire to conduct the survey. Future studies could compare the differences and similarities of negotiations in several countries, such as Asia's "four little dragons" or intra regions, such as Korea or Germany. 


\section{References}

Acuff, F. L. (1997). How to negotiate anything with anyone anywhere around the world. New York: AMACOM.

Ary, D., Jacobs, L. C. \& Razavier, A. (1996). Introduction to Research in Education, $5^{\text {th }}$ edition. Florida: Harcourt Brace College.

Barbash, I. \& Taylor, L. (1997). Cross-cultural filmmaking. Berkeley and Los Angeles, California: University of California Press.

Bjerke, B. V. (1999). Book review: Business decision making in China. Asia Pacific Journal of Management, 16(1), 178.

Bray, M. \& Qin, G. (2001). Comparative education in greater China: contexts, characteristics, contrasts and contributions. Comparative Education, 37(4), 451-473.

Casse, P. \& Deol, S. (1985). Managing intercultural negotiations: Guidelines for trainers and negotiators. Washington, DC: International Society for Intercultural Educa.

Crawford, D. (2000). Chinese capitalism: Cultures, the southeast Asian region and economic globalization. Third World Quarterly, 21(1), 69-87.

Cui, G. (1998). The emergence of the Chinese economic area (CEA): A regoicentric approach to the markets. Multinational Business Review, 6(1), 63-73.

Demers, J. (2002). Negotiating skills can be learned: An increasing number of Canadian universities are offering courses on the art - and the science - of negotiations. CMA Management, 76(8), 33. Retrieved April 13, 2004, from ProQuest database.

Evans, W. A., Hau, K. C. \& Sculli, D. (1989). A cross-cultural comparison of managerial styles. The Journal of Management Development, 8(3), 5-14.

Faure, G. O. \& Sjostedt, G. (1993). Culture and negotiation: An introduction.

Foroughi, A. (1998). Minimizing negotiation process losses with computerized negotiation support systems. Journal of Applied Business Research, 14(4), 15-27.

Fraser, C. \& Zarkada-Fraser, A. (2002). An exploratory investigation into cultural awareness and approach to negotiation of Greek, Russian and British managers. European Business Review, 14(2), 111-128.

Gay, L. R. \& Airasian, P. (2000). Educational Research: Competencies for analysis and application. Upper Saddle River, NJ: Prentice Hall.

Gilsdorf, J. W. (1997). Metacommunication effects on international business negotiation in China. Business Communication Quarterly, 60(2), 20-38.

Goodwin, L. D. \& Goodwin, W. L. (1999). Measurement myths and misconceptions. School Psychology Quarterly, 14, 408-427.

Graham, J. L. (1987). A theory of interorganizational negotiations. Research in Marketing, 9, 163-183.

Graham, J. L., Mintu, A. T. \& Rodgers, W. (1994). Explorations of negotiation behaviors in ten foreign cultures using a model developed in the United States. Management Science, 40(1), 72-95.

Grossnickle, J. \& Raskin, 0. (2001). The handbook of online marketing research. New York, NY: The McGraw-Hill Companies, Inc.

Gulbro, R. D. \& Herbig, P. (1994). The effect of external influences in the cross-cultural negotiation process. Journal of strategic change, 3, 329-340.

Hair, J. F., Anderson, R. E., Tatham, R. L. \& Black, W. C. (1998). Multivariate data analysis (5th ed.). Boston, MA: Pearson Education Inc.

Hall, E. (1976). Beyond culture. Garden City, NY: Anchor Press/Double Day.

Hayhoe, R. (1999). China's universities 1895-1995: a century of cultural conflict (Hong Kong, Comparative Education Research Centre, The University of Hong Kong).

Hodson, J. (2003). A case for American studies: The Michael Fay affair, Singapore-US relations, and American studies in Singapore. American Studies International, 41(3), 4-30.

Hoffmann, G. (2001). When scientists or engineers negotiate. Research Technology Management, 44(6), 13-16.

Howard, J. A., Blumstein, P. \& Schwartz, P. (1986). Sex, power, and influence tactics in intimate relationships. Journal of Personality and Social Psychology, 51(1), 102-109.

International Tax Review. (2007). Cultural evolution: the tax business in China. London: International Tax Review.

Janosik, R. J. (1987). Rethinking the culture-negotiation link. Negotiation Journal, 3, 385-395.

Kemenade, W. V. (1998). China, Hong Kong, Taiwan, Inc.: the dynamics of a new empire. Center for Strategic and International Studies (CICS) and Massachusetts Institute of Technology. 
Korobkin, R. (2000). A positive theory of legal negotiation. George Law Journal, 88(6), 1789-1732.

Kumar, R., Markeset, T. \& Kumar, U. (2004). Maintenance of machinery: Negotiating service contracts in business-to-business marketing. International Journal of Service Industry Management, 15(3/4), 400-421.

Li, J. \& Tsui, A. S. (2002). A citation analysis of management and organization research in the Chinese context: 1984-1999. Asia Pacific Journal of Management, 19(1), 87.

Lin, R. (2006). Multivariate analysis: SPSS operation and application. Taipei: BestWise.

Manning, T. \& Robertson, B. (2003). Influencing and negotiating skills: Some research and reflections - Part I: Influencing strategies and styles. Industrial and Commercial Training, 35(1), 11-16.

Mintu-Wimsatt, A. \& Gassenheimer, J. B. (2000). The moderating effects of cultural context in buyer-seller negotiation. The Journal of Personal Selling \& Sales Management, 20(1), 1-9.

Mintu-Wimsatt, A. \& Gassenheimer, J. B. (2002). The impact of demographic variables on negotiators' problem-solving approach: A two country study. Journal of Marketing Theory and Practice, 10(1), 23-35.

Nardi, N. K. (2006). What makes an effective negotiator? A phenomenological look at the Dominican Republic. Paper presented at the Academy of International Business Southeast, USA, 1-18.

Neslin, S. \& Greenhalgh, L. (1983). Nash's theory of co-operative games as a predictor of the outcomes of buyer-seller negotiations: an experiment in media purchasing. Journal of Marketing Research, 20(4), 368-379.

Ogden, S. (1998). China briefing: The contradictions of change. The Journal of Asian Studies, 57(2), 499-452.

Osman-Gani, A. M. \& Tan, J. S. (2002). Influence of culture on negotiation styles of Asian managers: An empirical study of major cultural/ethic group in Singapore. Thunderbird International Business Review, 44(6), 819-840.

Peterson, R. M. \& Lucas, G. H. (2001). Expanding the antecedent component of the traditional business negotiation model: Pre-negotiation literature review and planning-preparation propositions. Journal of Marketing Theory and Practice, 9(4), 37-50.

Post, D. (2004). Family resources, gender, and immigration: Changing sources of Hong Kong educational inequality, 1971-2001.Social Science Quarterly, 85(5), 1238-1259.

Prasad, E. \& Rumbaugh, T. (2003). Beyond the great wall. Finance \& Development, 40(4), 46.

Pullins, E. B., Haugtvedt, C. P., Dickson, P. R., Fine, L. M. \& Lewicki, R. J. (2000). Individual differences in intrinsic motivation and the use of cooperative negotiation tactics. The Journal of Business \& Industrial Marketing, 15(7), 466-486.

Rubin, J. Z. \& Brown, B. R. (1975). The social psychology of bargaining and negotiation. New York: Academic Press.

Schehr, R. C. \& Milovanovic, D. (1999). Conflict mediation and the postmodern: Chaos, catastrophe, and psychoanalytic semiotics. Social Justice, 26(1), 208-233.

Schein, E. H. (1997). Organizational culture \& leadership. CA: Jossey-Bass Inc.

Schneider, S. C. \& Barsoux, J. L. (2003). Managing Across Cultures. London, England: Pearson Education Limited.

Sheehan, K. B. (2001). Email survey response rates: A review. Journal of Computer Mediated-Communication, 6(2). Retrieved from http://www.ascusc.org/ jcmc/vol6/issue2/sheehan.html

Simintiras, A. C. \& Thomas, A. H. (1998). Cross-cultural sales negotiations: A literature review and research propositions. International Marketing Review, 15(1), 10-36.

Stuhlmacher, A. F. \& Walters, A. E. (1999). Gender differences in negotiation outcome: A meta-analysis. Personnel Psychology, 52(3), 653-678.

Wallen, N. E. \& Fraenkel, J. R. (2001). Educational Research: A guide to the process (2nd ed.). Mahwah, NJ: Lawrence Erlbaum Associates, Inc.

Wang, Q. \& Zhang, W. (2004). China's potato industry and potential impacts on the global market. American Journal of Potato Research, 81(2), 101-110.

Ziegler, D. (1997). Ready to face the world. The Economist, 342(8), C3-6. 